\title{
The Remote Learning Experience in Lebanon: Learners' Attitudes and Practices
}

\author{
Joumana Assaf ${ }^{1,2 \star(D)}$, Loubna Nehmeh ${ }^{2,3}$ (1)
}

\begin{abstract}
${ }^{1}$ Doctoral School of Sciences and Technology (EDST), PRASE, Lebanese University, LEBANON
${ }^{2}$ Center for Educational Research and Pedagogical Development, CRPD, Dekwaneh, LEBANON

${ }^{3}$ Department of English Language and Literature, Lebanese University, Saida, LEBANON

*Corresponding Author: jassaf@crdp.org
\end{abstract}

Citation: Assaf, J., \& Nehmeh, L. (2022). The Remote Learning Experience in Lebanon: Learners' Attitudes and Practices. Pedagogical Research, 7(1), em0115. https://doi.org/10.29333/pr/11551

ARTICLE INFO

Received: 5 Jul. 2021

Accepted: 3 Jan. 2022

\begin{abstract}
Despite its flexibility, remote learning is a complex process which depends on several elements considered as pillars of online learning and which affect each other. The purpose of the study is to reveal the learners' feeling of social isolation while learning remotely as well as the effectiveness of online communication channels in ensuring learning support through content sharing with teachers and colleagues. Moreover, the learners' self-regulation skills were reflected through their practices while learning as well as through the value of being a part of the digital community. The learners' evaluation of their remote learning experience, their attitudes towards passing through this experience again and their suggestions to improve virtual learning were also examined in the last section of the survey.

This study sheds light on the social isolation barrier while learning online as $49 \%$ of students reported that they always felt isolated. In fact, this disconnectedness was not compensated by online communication especially that around $31 \%$ of learners declared that using on line communication with teachers and colleagues never helps them with the learning process. Morever, $55 \%$ of learners stated that they never prepare questions before joining online discussions or watching videos in virtual learning. Therefore, the lack of teaching presence - associated with the lack of learners' regulation skills - leads to the absence of learning presence in online learning. The results reflected the perspectives and attitudes of learners towards online learning as $44 \%$ of learners described their online learning experience as "bad, unsuccessful, and characterized by failure". Moreover, $63 \%$ of learners stated that they were not interested to pass through the online learning experience again. To improve the implementation of online learning, $55 \%$ of respondents suggested enhancing the teaching strategies whereas $47 \%$ of participants recommended improving the infrastructure and providing the required facilities. So, for integrating online learning, a viable strategy needs to be developed and made aligned with all the opportunities and challenges of online learning in the Lebanese context.
\end{abstract}

Keywords: learners' perceptions, social isolation, teacher presence, learning presence, online communication channels

\section{INTRODUCTION}

Due to the current situation, there was a shift from traditional classroom learning to online learring. Accordingly, e-learning models started to reform the delivery of the instructional content as well as the learning activities and to establish new social communication means. This created a new learning environment which had to be investigated in terms of its difference from the traditional one. The problem remains that there was minimal research on learners' attitudes towards the online learning environment before COVID-19 pandemic (Reis, 2010). According to Adnan (2018), there is evidence that students tend to understand better if multimedia tools are integrated into teaching. Yet, such a process is not free of complications.

Before COVID-19, learning took place completely inside the classrooms since the Lebanese Ministry of Education and Higher Education (MEHE) does not acknowledge degrees obtained by learners through distance learning and rejects their equivalence.

Few weeks after school lockdowns, the government took a swift action and trained public school teachers on Microsoft Teams but it gave them the freedom to choose any available platform. According to MEHE, the purpose of online teaching was to keep students in the learning atmosphere as much as possible during school lockdowns (Atallah \& Bou Melhem, 2020).

So, most learning took place asynchronously where teachers recorded their sessions and sent them to students through Microsoft Teams or WhatsApp groups. Many of them sent power point presentations with or without audios. Zoom, on the other hand, was mostly used for synchronous learning or discussions in addition to the WhatsApp groups (Al Rouadi \& Anouti, 2020). 
According to a survey on national education responses launched by UNESCO, UNICEF, and the World Bank (2020) as responses to COVID-19 school closures, there were three delivery channels for remote-learning in Lebanon: a government-supported digital website with content, the TV programs, and paper-based responses with take-home packages. Indeed, the platform launched by the Lebanese government broadcasted only few resources which were restricted to Maths and Sciences since the Lebanese curriculum is not digital and it goes back to 1997. Futhermore, the TV program was only addressed to Grade 9 and Third Secondary learners. It broadcasted some teaching sessions and recorded videos on Télé Liban (TL); the public television network, owned by the Lebanese government.

For these iniatives taken by the government, there is no collected data at the national level showing the accessibility and the effectiveness of the delivered resources. Moreover, there are no studies which reflect the students' perceptions towards online learning, and the researches conducted in Lebanon focused only on the teachers' perceptions (Farah \& Frayha, 2021; Hanadi, 2021).

In light of what was presented above, this study aims to examine the Lebanese learners' perceptions and attitudes towards online learning as well as their practices in online learning by surveying 928 Grade 9 and Third Secondary students. The findings of this study will help to assess the pedagogical approach of planning for online lessons, designing online activities and delivering online content in the future.

So, in this study, the researchers sought to scrutinize the practices adopted by students for keeping themselves in the learning atmosphere; which reflects their engagement and their behaviors as self learners and responsible persons. Moreover, the researchers aimed to find out more about learners' perceptions and attitudes through the content analysis of their responses to the open questions, in relation to how they would describe the online learning experience, express their willingness to go through this experience again, and make recommendations for better implementation of online learning hence forward.

More specifically, this study aims to answer the following research questions:

1. What were the Lebanese students' attitudes about social isolation in remote learning?

2. What were the practices of Lebanese students towards remote learning?

3. What were the perceptions of Lebanese learners of the online learning experience?

4. What were the Lebanese learners' attitudes towards going through the remote learning experience again?

5. What recommendations were given by Lebanese learners for improving the remote learning process?

For all these research questions, the study illustrates whether there is a statistical difference between Grade 9 and Third Secondary learners or not.

\section{LITERATURE REVIEW}

Schools are considered the hubs for social activity and human interactions. On that account, school closures deprived students of some kinds of communication and socialization considered essential to learning, development and creativity (UNESCO, 2020). Due to the COVID-19 pandemic, distance learming is generally characterised by the following features.

\section{Social Isolation}

Flack et al. (2020) conducted a survey about the impact of the COVID-19 pandemic on teaching and learning. The respondent teachers, who have used technologies synchronously such as Zoom or Skype, stated that they were not sure that these technologies could support all aspects of teaching since they are not created specifically for this purpose.

This is why social disconnection will have an impact on students' social-emotional wellbeing; a concern that has to be addressed by the educational stakeholders when taking decisions for the upcoming year or once students are back to attending their classes physically. Researchers found by comprehensive meta-analysis that social cohesion within classrooms is positively associated with learning outcomes (Bücker et al., 2018). Moreover, further studies revealed that the lack of socialization is the central obstacle caused by the transition to online learning (Zhang \& Lin, 2020).

Due to the social relationships distinguishing physical classrooms, face-to-face education strengthens students' sense of belonging to the learning environment and process (Luo et al., 2017). So, the transactional distance perception weakens the communication between students and teachers which may cause a psychological gap (Moore \& Kearsley, 2012).

Hence, the effectiveness of online learning depends on the social presence which is related to students' motivation and engagement and on the learning presence which is affected by learner's self-regulation skills.

\section{Social Presence}

According to McKeon (2014), the relationship between the teacher and the learners is vital to a great extent in any learning environment. So, students' online learning is influenced by three main factors which are interaction, support and motivation. The satisfaction on learning is highly influenced by enjoyment that in turn is affected by students' interaction (Peters et al., 2012). The personal relationships with teachers and peers enhance motivation and learning (Holmberg, 2007).

\section{Learning Presence}

According to Shea et al. (2012), learning presence refers to students' proactive use of specific processes such as goal setting, strategy selection and personal monitoring of effectiveness. It indicates the exercise of control rather than compliance and 
passivity. It articulates popular beliefs about the importance of self-direction in online and blended learning environments. The learning presence is strongly related to the learners' self-regulation skills.

\section{Learners' Self-Regulation Skills}

Zimmerman (2002, p. 65) defines self-regulation as "the self-directive process through which students transform their mental abilities into academic skills". Hence, the self-generated feelings, behaviors and thoughts are those which direct students towards reaching their goals. However, in remote learning, there is a necessity that learners possess self-regulation skills due to the selfdirected nature of online learning.

So, self-regulated online students are capable of regulating their own learning environment, managing their time and interacting effectively with peers to maximize learning.

Moreover, to ensure a high quality of online teaching and learning, teachers' professional development on technology tools and the pedagogy of online teaching is a must.

\section{Pedagogy of Online Teaching}

Since online learning occurs at home, the effectiveness of education depends on the teacher presence through providing clear instructions and using different communication channels with the students. So, the teacher presence is ensured by establishing effective communication means with students. These efforts from teachers to keep students involved in their learning will be useless without the learning presence is important.

This is why the Community of Inquiry (Col) Framework (Garrison \& Arbaugh, 2007; Garrison \& Cleveland-Innes, 2005; Garrison \& Vaughan, 2008) that previously consisted of three interconnected presences (social, cognitive and teaching) was revised by Pool (2017). In Col framework, the teaching presence is defined as the integrating force that structures and leads the educational process in a constructive and collaborative atmosphere. It is essential in establishing the social presence by creating an atmosphere of meaningful communication, cohesive discourse and personal connections. The social presence refers to the ability to connect with members of a community on a personal level; it is a mediating factor that provides context for the educational process. The cognitive presence is defined as the process of constructing meaning through collaborative inquiry and its relationship with the teaching presence becomes clear when students are assigned tasks that require them to move through the elements of practical inquiry (triggering event, exploration, integration and resolution).

Once students are engaged, the teacher presence would have a significant role in facilitating and directing students' learning for the sake of reaching a successful learning experience (Garrison \& Vaughan, 2008). This learning presence is influenced by selfregulation skills which include time-management, self discipline, goal setting, self-reliance and division of tasks (Banerjee, 2011; Brunner et al., 2015).

In fact, the success of online learning does not depend only on implementing an e-pedagogy but also depends on the availability of a strong infrastructure, suitable technological tools and abundant digital materials.

\section{Infrastructure and Technological Tools}

The shift to online learning means the transition from a conventional class to a virtual class which requires the use of internet connection and technological tools (Means et al., 2014). Therefore, the infrastructure such as electricity, internet, and access to technological tools are among the top problems which prevent implementing online learning properly.

\section{High Quality of Digital Instructional Resources}

The learning presence is highly achieved when learners are given the opportunity to interact with instructional materials and to draw meanings from their own interactions (McLeod, 2019). Hence, the quality of instructional materials matters and it is highly needed during the process of teaching in virtual classes.

Finally, though the effect of the parents' socio-economic status on students' learning is out of the scope of this study, it is expected to widen the gap among students of lower grades (Burgess \& Sievertsen, 2020).

\section{METHOD}

\section{Research Design}

Since the aim of the study is to examine the perceptions and attitudes of Lebanese Grade 9 and Third Secondary learners towards the online experience as well as scrutinize their online learning practices, the researchers used empirical data to answer the research questions. Therefore, the researchers followed the Mixed Method in collecting and analysing both quantitative and qualitative data. The quantitative approach was used to track frequencies regarding the attitudes of students towards social isolation and their practices while learning online. So, tables of frequencies and percentages, as well as those of cross-tabulations were used to present categorical variables. To answer the research questions, the researchers conducted Chi-Square tests of independence to investigate the relationships between the grade level (Grade 9 and Third Secondary) and other categorical variables and to test their strength by Chi Square meausres of correlation. For the three open-ended questions, the researchers used thematic content analysis to examine qualitative data based on the students' responses and Chi-Square test for nominal data. 


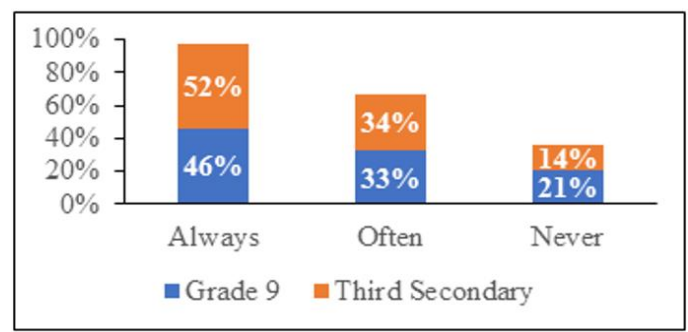

Figure 1. Students' degree of feeling socially isolated during remote learning

\section{Data Collecting Tool}

The instrument utilized to collect data was an online survey which consists of three Sections. Section 1 sought to collect general information about the respondents including the type of schools they learn at and their grade level. Information about respondents' gender and the language of instruction were not collected since they fall out of the scope of the present study. In Section 2, learners were asked about social isolation during online learning in addition to their practices towards this new mode of learning. In Section 3, the attitudes of learners towards online learning were tested through asking them to describe their online learning experience if they are interested to go through this experience again. They were also asked to make recommendations for better implementation of online learning in case it would be adopted in the future.

\section{Data Analysis}

After collecting and cleaning data and sorting responses by question, the researchers conducted a range of statistical analyses by using SPSS (version 19). Based on the findings, data were interpreted, the research questions were answered, conclusions were drawn, and recommendations were made.

\section{Validity and Reliability}

To check the validity of the survey, it was shared with four raters: three university professors and to a statistician. To estimate the reliability coefficient, 10 students-who were not a part of study- were asked to respond to the survey questions at two different periods of time so that the researchers could find the correlation between their scores.

\section{Sampling}

The study sample included 928 Grade 9 and Third Secondary learners of formal academic learning in the Lebanese educational system. They are learning according to the Lebanese curricula issued in 1997. Grade 9 represents the end of Cycle III of Basic Education whereas the Third Secondary represents the end of the Secondary Stage and subsequently of school education. Regarding the respondents, around half of them (51\%) were enrolled in Grade 9 while the second half (49\%) were in the Third Secondary, noting that both the former and the latter sit for Official Exams at the end of their academic year. This sample is quite a representative of the Lebanese learners' population since the percentage of Grade 9 learners is approximately equal to that found in the population where $58 \%$ of learners $(\mathrm{N}=61,241)$ were enrolled in Grade 9 as compared to approximately $42 \%$ of learners $(\mathrm{N}=44,107)$ who were enrolled in the Third Secondary (Statistical Bulletin issued by CRDP, 2020). Around $56 \%$ of partcipants $(\mathrm{N}=518)$ were from public schools and $44 \%$ were from private ones $(\mathrm{N}=410)$. For the academic year 2019-2020, the percentage of learners enrolled in public schools was $32 \%$ (Statistical Bulletin issued by CRDP, 2020). On that account, this study will shed more light on the perceptions of public school learners who mostly live in families which have a lower socio-economic status.

\section{FINDINGS}

Since one of the major problems of online learning is social isolation, this feeling of disconnectedness was explored in Q1 of Section 2. In this question, as Figure 1 illustrates, students had to state their opinion about the statement "Online lessons make me feel isolated because there is not any kind of interaction" by selecting one of the three categories: Always, Often, and Never.

A test of correlation was run to examine the relationship between the students' feeling of social isolation during online learning and their grade level. The results revealed that there was a weak relationship between these two variables, which was statistically different, $\chi^{2}(2, \mathrm{~N}=916)=7.369, \mathrm{p}=.025<0.05, \Phi_{C}=.090$.

Q2 of Section 2 consists of 15 multiple response items with "Always", "Often," and "Never" as the outcome variables. A reliability analysis was carried out and Cronbach's alpha gave acceptable reliability, $\alpha=0.842$. These items reflect the practices leaners adopted in online learning as well as their attitudes. All the items appeared to be worthy of retention leading to a decrease in alpha if deleted.

These items made it possible to explore how effective online communication platforms were for learners to deeply understand the materials delivered by their teachers as well as to comunicate with their teachers and their peers when they asked for help and shared their understanding. Such items are:

"Using online communication platforms helps me to understand the lessons very well"; "Online communication with my teachers helps me with the learning process"; "Online communication with my colleagues helps me with the learning 
Table 1. The items of $\mathbf{Q 2}$ in Section 2

\begin{tabular}{cl}
\hline Items (I) & The items of Q2 in Section $\mathbf{2}$ \\
\hline $\mathbf{I 1}$ & Using online communication channels helps me to understand the lessons very well. \\
\hline $\mathbf{I 2}$ & Online communication with my teachers helps me with the learning process. \\
\hline $\mathbf{I 3}$ & Online communication with my colleagues helps me with the learning process. \\
\hline $\mathbf{I 4}$ & I choose the location where I study to avoid distractions. \\
\hline $\mathbf{I 5}$ & I choose a time with little distractions to study my online lessons. \\
\hline $\mathbf{I 6}$ & I am doing the required assignments. \\
\hline $\mathbf{I 7}$ & I try to take thorough notes because notes are more important for learning online than in a regular classroom. \\
\hline $\mathbf{I 8}$ & Although we do not have to attend daily classes, I still try to distribute my studying time evenly across days. \\
\hline $\mathbf{I 1 0}$ & I prepare questions before joining the online discussion or watching the video. \\
\hline $\mathbf{I 1 1}$ & I do more exercises in addition to the assigned ones to master the content. \\
\hline $\mathbf{I 1 2}$ & I share my problems with my classmates online so we know what we are struggling with and how to solve our problems. \\
\hline I13 & I communicate with my classmates to find out what I am learning that is different from what they are learning. \\
\hline I14 & I ask for the help of my teachers through different means (email, Facebook or WhatsApp). \\
\hline I15 & I believe that being a part of such an online community is important for me. \\
\hline
\end{tabular}

process"; "I share my problems with my classmates online so we know what we are struggling with and how to solve our problems"; "I communicate with my classmates to find out what I am learning that is different from what they are learning"; and "I ask for the help of my teachers through different means (email, Facebook, or WhatsApp)."

Nonetheless, other items such as

"I choose the location where I study to avoid too many distractions"; "I choose a time with little distractions to study my online lessons";

and

"Although we do not have to attend daily classes, I still try to distribute my studying time evenly across days"

showed the practices followed by students to manage their learning as they usually did before COVID-19. Furthermore, the practices

"I am doing the required assignments"; "I try to take thorough notes because notes are more important while learning online than in a regular classroom"; "I prepare questions before joining the online discussion or watching the video"; "I do more exercises in addition to the assigned ones to master the content";

and

"I summarize my online learning to examine my understanding of what I have learned",

showed learners' responsibility towards their learning and how seriously they took online learning since these participants (Grade 9 and Third Secondary students) were supposed to sit for an Official Exam at the end of the academic year 2019-2020.

Finally, the perspectives of students towards the value of being a part of the digital world community were reflected through their responses to the item

"I believe that being a part of such an online community is important for me."

A test of correlation was run to examine the relationship between learner's grade level and the efficacy of online communication platforms in helping students to deeply understand their lessons during remote learning. There was a moderate, positive correlation between these two variables, which was statistically different, $\chi^{2}(2, \mathrm{~N}=923)=15.558, \mathrm{p}<.001, \Phi_{C}=.130$.

Another test of correlation was run to determine the relation between learner's grade level and their responsibility of doing the required assignments during remote learning. There was a moderate, positive correlation between these two variables, which was statistically different, $\chi^{2}(2, \mathrm{~N}=897)=19.192, \mathrm{p}<.001, \Phi_{C}=.146$.

The items of $\mathbf{Q} 2$ in Section $\mathbf{2}$ are presented in Table 1. The responses of Grade 9 and Third Secondary learners to the items of Q2 in Section 2 are presented in frenquency $(\mathrm{N})$ and in (\%) in Table 2 while those which were statistically different between Grade 9 and Third Secondary learners are illustrated in Figure 2.

Section 3 consists of three short questions which are:

Q1: How do you evaluate the remote learning experience?

Q2: Are you interested to go through such an experience again?

Q3: What suggestions do you have to improve this experience? 
Table 2. Students' online learning practices

\begin{tabular}{|c|c|c|c|c|c|c|c|}
\hline \multirow{2}{*}{$\begin{array}{l}\text { Items of Q2 } \\
\text { in Section } 2\end{array}$} & \multicolumn{3}{|c|}{ Grade 9 learners (N) } & \multicolumn{3}{|c|}{ Third secondary learners (N) } & \multirow{2}{*}{ Total (N) } \\
\hline & "Always" (\%) & "Often" (\%) & "Never" (\%) & "Always" (\%) & "Often" (\%) & "Never" (\%) & \\
\hline I1 & $46(9.7 \%)$ & $309(65.3 \%)$ & $118(24.9 \%)$ & $21(4.7 \%)$ & $343(76.2 \%)$ & $86(19.1 \%)$ & 923 \\
\hline 12 & $87(18.6 \%)$ & $237(50.7 \%)$ & $143(30.6 \%)$ & $72(16.1 \%)$ & $248(55.5 \%)$ & $127(28.4 \%)$ & 914 \\
\hline 13 & $0(0 \%)$ & $312(67.4 \%)$ & $151(32.6 \%)$ & $0(0 \%)$ & $314(70.2 \%)$ & $133(29.8 \%)$ & 910 \\
\hline 14 & $247(53.3 \%)$ & $170(36.7 \%)$ & $46(9.9 \%)$ & $230(51.7 \%)$ & $166(37.3 \%)$ & $49(11.0 \%)$ & 908 \\
\hline 15 & $198(42.9 \%)$ & $203(43.9 \%)$ & $61(13.2 \%)$ & $172(39.2 \%)$ & $195(44.4 \%)$ & $72(16.4 \%)$ & 901 \\
\hline 16 & $249(54.6 \%)$ & $169(37.1 \%)$ & $38(8.3 \%)$ & $183(41.5 \%)$ & $191(43.3 \%)$ & $67(15.2 \%)$ & 897 \\
\hline 17 & $183(39.8 \%)$ & $184(40.0 \%)$ & $93(20.2 \%)$ & $192(43.3 \%)$ & $176(39.7 \%)$ & $75(16.9 \%)$ & 903 \\
\hline 18 & $132(28.4 \%)$ & $185(39.8 \%)$ & $148(31.8 \%)$ & $99(22.6 \%)$ & $198(45.1 \%)$ & $142(32.3 \%)$ & 904 \\
\hline 19 & $55(11.9 \%)$ & $168(36.3 \%)$ & $240(51.8 \%)$ & $64(14.8 \%)$ & $144(33.3 \%)$ & $225(52.0 \%)$ & 896 \\
\hline 110 & $87(18.9 \%)$ & $225(48.9 \%)$ & $148(32.2 \%)$ & $77(17.6 \%)$ & $209(47.8 \%)$ & $151(34.6 \%)$ & 897 \\
\hline I11 & $129(28.0 \%)$ & $204(44.3 \%)$ & $127(27.6 \%)$ & $129(29.6 \%)$ & $172(39.4 \%)$ & $135(31.0 \%)$ & 896 \\
\hline I12 & $110(23.9 \%)$ & $194(42.2 \%)$ & $156(33.9 \%)$ & $88(20.2 \%)$ & $185(42.5 \%)$ & $162(37.2 \%)$ & 895 \\
\hline I13 & $79(17.2 \%)$ & $183(40.0 \%)$ & $196(42.8 \%)$ & $83(19.1 \%)$ & $156(35.9 \%)$ & $196(45.1 \%)$ & 893 \\
\hline I14 & $147(32.1 \%)$ & $211(46.1 \%)$ & $100(21.8 \%)$ & $150(34.2 \%)$ & $203(46.2 \%)$ & $86(19.6 \%)$ & 897 \\
\hline $\mathbf{I 1 5}$ & $188(42.3 \%)$ & $179(40.3 \%)$ & $77(17.3 \%)$ & $159(37.0 \%)$ & $188(43.7 \%)$ & $83(19.3 \%)$ & 874 \\
\hline
\end{tabular}

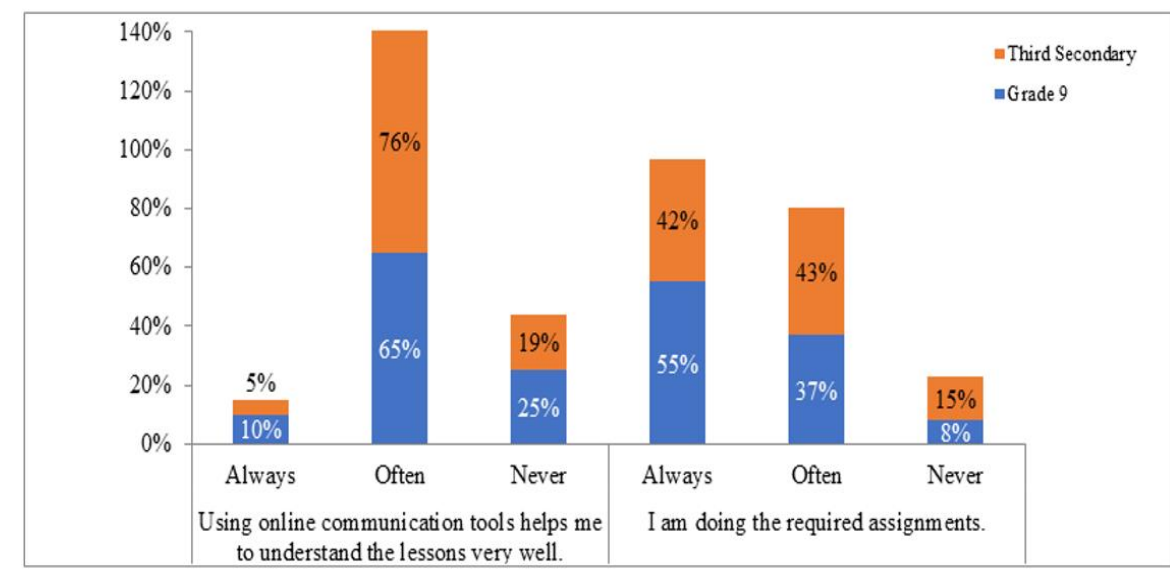

Figure 2. Students' responses to the items whose results were statistically different between grade levels

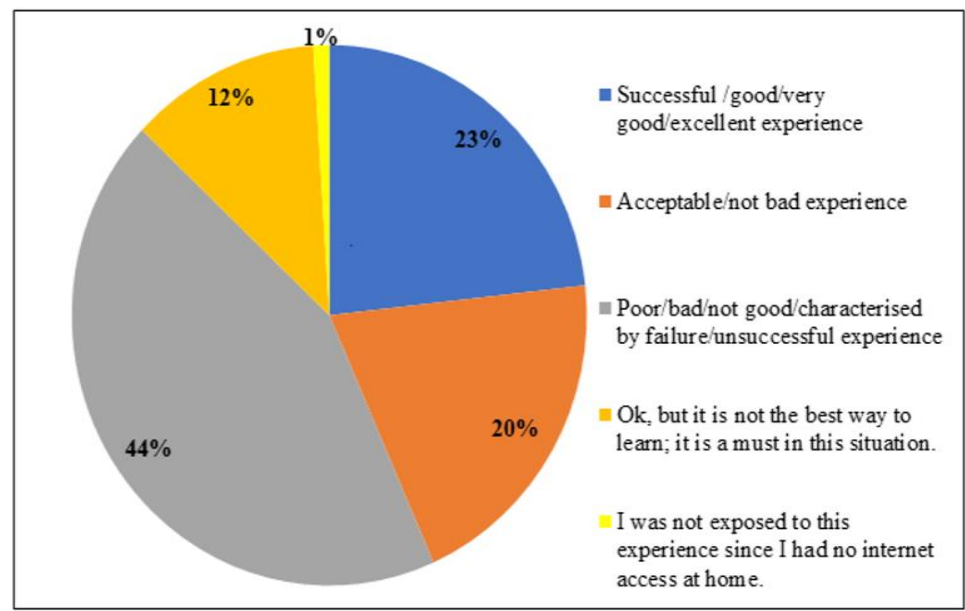

Figure 3. Students' responses regarding the online learning experience

For Question 1, the responses of 808 participants were distributed into 5 categories as illustrated in Figure 3 which indicates that $44 \%$ of learners described the remote learning as a poor/bad/not good/unsuccessful experience or as an experience characterised by failure compared to $43 \%$ of learners who described it either as a successful (23\%) or as an acceptable experience (20\%).

The results proved that no statistical difference was found between the outcome variables of Q1 and the grade level of learners. The responses of 416 Grade 9 and of 392 Third Secondary learners are presented in Figure 4. 


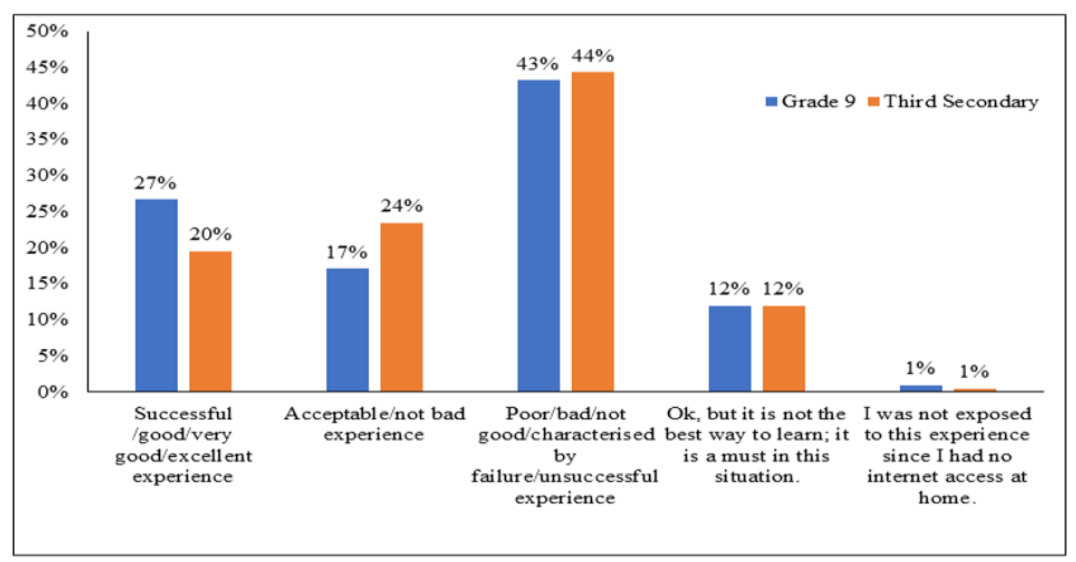

Figure 4. Students' responses regarding the online learning experience according to grade level

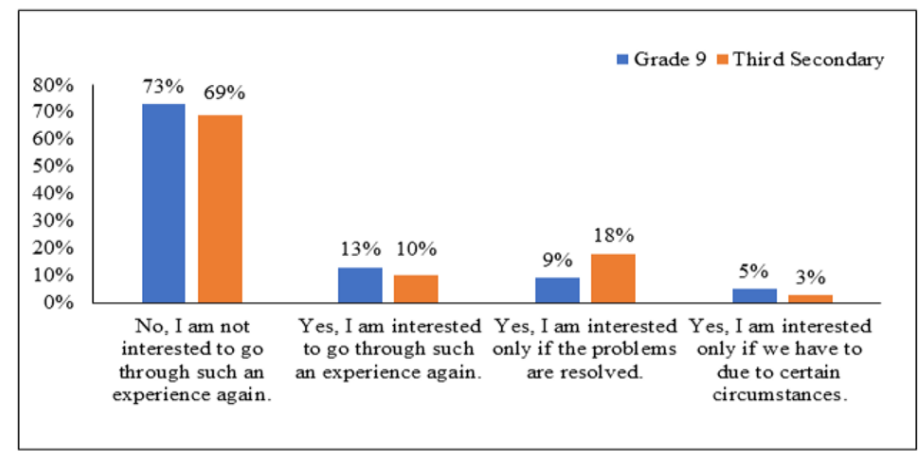

Figure 5. Students' willingness to pass through the online experience again according to grade level

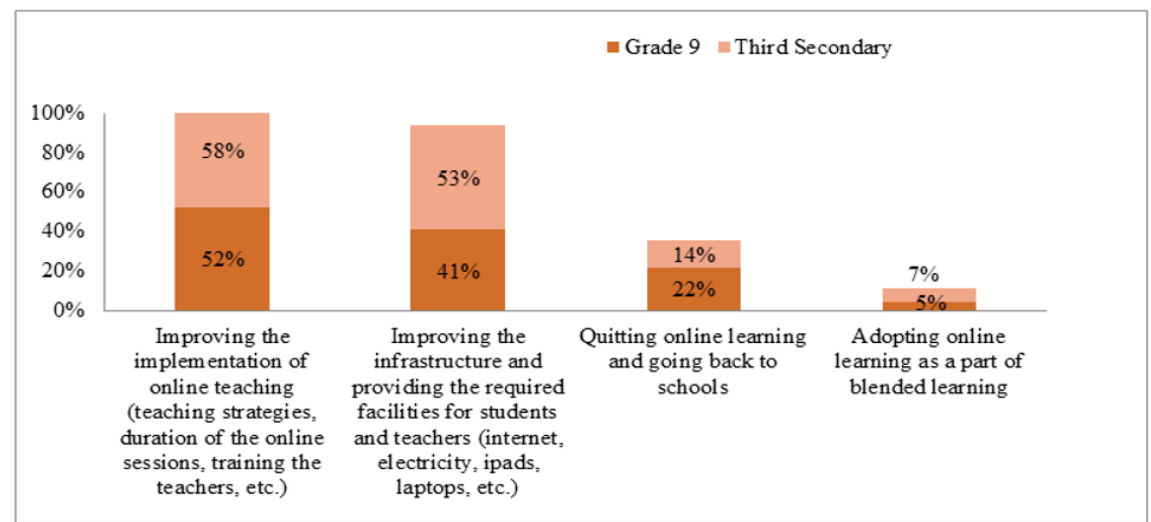

Figure 6. Students' recommendations according to grade level

For Question 2, 820 responses were distributed into 4 categories: 63\% of respondents were not interested to go through such an experience again in contrast to $10 \%$ who showed interest to go through it again; $12 \%$ who were interested only if the problems are resolved and $4 \%$ who were interested just in case they have to due to certain circumstances (pandemic...). A contingency table analysis between the variable of $\mathbf{Q} \mathbf{2}$ and the learners' grade level showed a moderate and positive correlation between these two variables, which was statistically different, $\chi^{2}(3, \mathrm{~N}=820)=17.279, \mathrm{p}=.001, \phi_{c}=145$. The distribution of responses to $\mathbf{Q} 2$ according to learners' grade is presented in Figure 5.

In Question 3 of Section 3, respondents were asked to make recommendations for improving remote learning in case it will be adopted in the future. So, 556 participants who were distributed almost equally across Grade 9 ( $N=282$ ) and Third Secondary $(N=274)$ responded to this question by giving one or more recommendations which were grouped into four categories. 32 respondents (5.8\%) showed preference to the blended model of teaching as they suggested adopting remote learning while returning physically to schools. 260 respondents (46.8\%) suggested improving the infrastructure and providing the required facilities for students and teachers (internet, electricity, ipads, laptops, etc.). 306 participants (55\%) suggested improving the strategy of implementing remote learning (teaching strategies, duration of the online sessions, training the teachers, etc.). Finally, 99 respondents (17.8\%) proposed giving up on remote learning and returning to schools.

A Chi-square test was run to examine the relation between the recommendations to improve the infrascture and to provide the required tools for remote learning and the learners' grade level. A moderate relationship was found between these variables which was statistically significant, $\chi^{2}(1, N=556)=8.227, p=.004<.01, \phi_{c}=.122$. As it can be seen in Figure 6 , the Third Secondary learners were more likely to give such a suggestion than Grade 9 learners. 


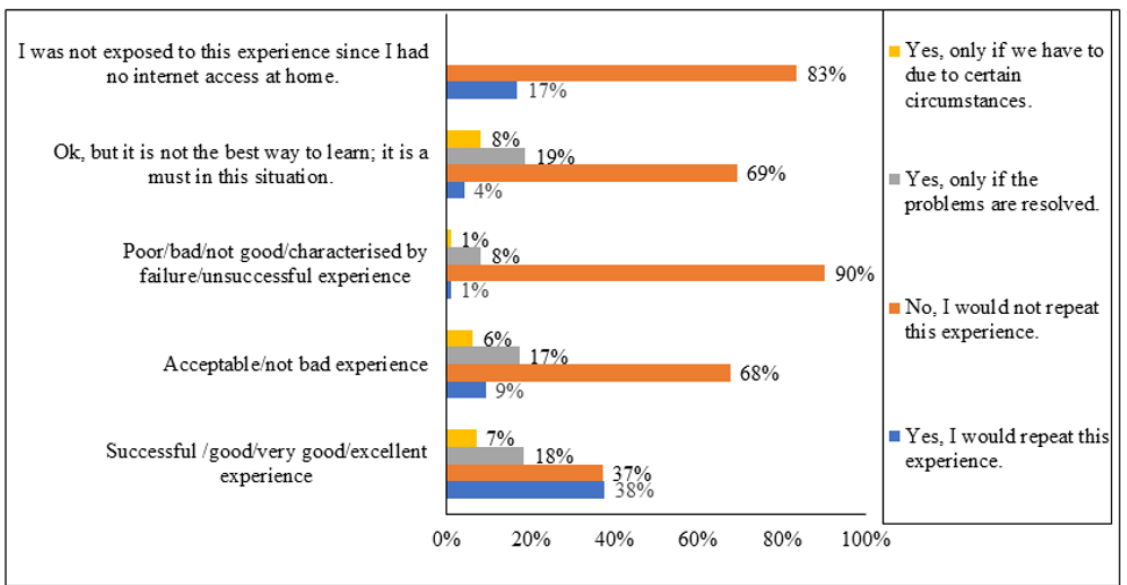

Figure 7. Correlation between students' evaluation of the online learning experience and their Interest to pass through it again

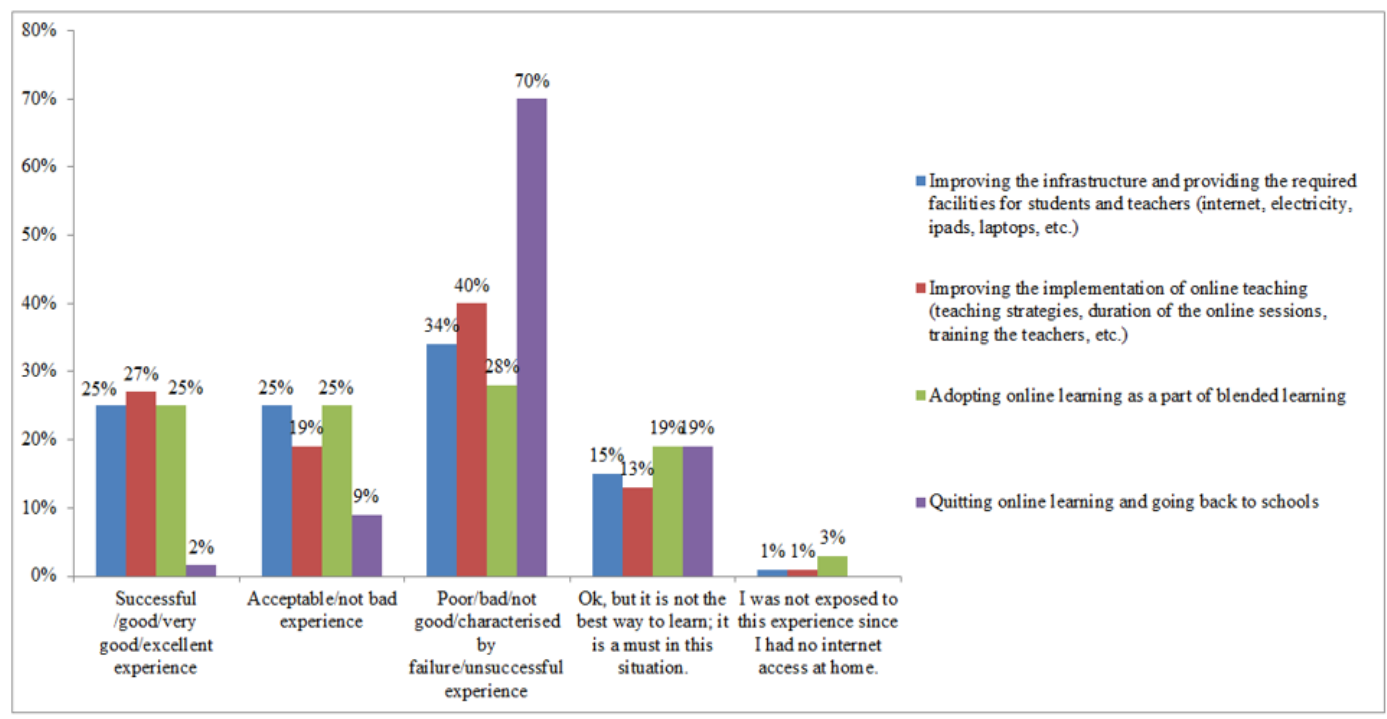

Figure 8. Correlation between students' evaluation of the online learning experience and their recommendations

Another Chi-square test was run to examine the relationship between the recommendation of quitting online learning and going back to schools and the learners' grade level. A moderate relationship was found between these variables which was statistically significant, $\chi^{2}(1, \mathrm{~N}=556)=5.772, \mathrm{p}=.017<.05, \phi_{c}=.101$. As it can be seen in Figure 6, Grade 9 learners were more likely to give such a recommendation than Third Secondary learners.

After that, we examined if there are relationships among the outcome variables of Q1, Q2, and Q3 of Section 3. So, a Chisquare test was run to examine the relationship between the outcome variables of $\mathbf{Q} \mathbf{1}$ and $\mathbf{Q 2}$. A statistically significant strong relationship was found between these variables, $\chi^{2}(12, \mathrm{~N}=804)=231.360, \mathrm{p}<.001, \phi_{c}=.310$, as it is demonstrated in Figure 7 .

To examine the relationship between the outcome variables of $\mathbf{Q} \mathbf{1}$ and $\mathbf{Q 3}$, a further Chi-square test was run. A moderate and statistically significant relationship was found between the variables of $\mathbf{Q} \mathbf{1}$ and the recommendations made to improve the infrastructure and to provide the required facilities to students and teachers, $\chi^{2}(4, N=552)=17.295, p=.002<.01, \phi_{C}=.177$.

An additional Chi-square test was run to examine the relationship between the outcome variables of $\mathbf{Q} \mathbf{1}$ and the recommendation to give up on remote learning and return to schools. A strong and statistically significant relationship was found between these variables, $\chi^{2}(4, \mathrm{~N}=552)=53.817, \mathrm{p}<.001, \phi_{c}=.312$. The correlation between outcome variables of $\mathbf{Q} \mathbf{1}$ and $\mathbf{Q} 3$ is presented in Figure 8.

\section{DISCUSSION AND SUGGESTIONS}

The purpose of this study is to explore the Lebanese learners' attitudes towards online learning along with their online learning practices by interpreting the responses of 928 Grade 9 and Third Secondary students. Morever, the influencing factors such as the feeling of social isolation and the effectiveness of online communication are examined through learners' responses.

Schools represent the communities where students establish personal connections with colleagues and teachers. In this sense, school closures made them feel isolated and disconnected as the human connections were replaced by online communication. The feeling of being isolated in remote learning was examined through learners' responses to Q1 in Section $\mathbf{2}$. 
So, around $82 \%$ of learners reported that they felt isolated while learning remotely by selecting the categorical variables "Often" and "Always" for the item "Online lessons make me feel isolated because there is not any kind of interaction" whereas only $18 \%$ of them declared that they "Never" felt isolated. This fact was highlighted in many studies (Bücker et al., 2018; Zhang \& Lin, 2020) since learning is a social act which depends on the teacher's presence and the student's presence; the two pillars of the teachinglearning process. Flack et al. (2020) clarify that students' social isolation was the top concern of teachers during the COVID-19 pandemic. These teachers ranked social isolation above learning loss as they expressed their anxiety about a loss of social connection with their students and a decrease in the effectiveness of their teaching practices. This refers to the fact that social cohesion between learners and teachers is positively associated with the learning outcomes.

Virtual learning offers new ways of online communication tools. Hence, its effectiveness in enhancing the learning process is investigated in Q2 of Section 2. Around 78\% of learners declared that using online communication channels help them to understand the lessons very well. This percentage was found correlated with the responses of $79 \%$ of learners who stated that they asked for the help of their teachers through different means of online communication (email, Facebook, or WhatsApp). Furthermore, around $70 \%$ of learners stated that using online communication with their teachers and colleagues helps them with the learning process.

In online learning, there are more flexible learning modalities better opportunities for self-paced learning which allow individualised and personalised learning experiences. This increases the level of learner's motivation which subsequently improves learning outcomes (Bakia et al., 2012). So, students need to be self-motivated (Jackson, 2009) in this new learning environment with a different learning approach. This was revealed through learners' practices while studying online. The learners' practices to better understand the online lessons delivered by their teachers were assessed through their responses to the items of Q2 in Section 2.

The results showed that around $90 \%$ of learners had "Always" or "Often" chosen an appropriate place to study. These findings were correlated with $85 \%$ of learners who had "Always" or "Often" chosen a time with few distractions for studying their online lessons.

Nevertheless, almost $81 \%$ of learners "Always" or "Often" took thorough notes because they considered this practice more important in online learning than in a regular classroom.

For the item "I share my problems with my classmates online so that we could know what we are struggling with and how to solve our problems", the results showed that around 35\% of learners chose "Never". This percentage increased to $44 \%$ when learners responded "Never" to the item "I communicate with my classmates to find out what I am learning that is different from what they are learning". For the item "I prepare questions before joining the online discussion or watching the video", 52\% of learners "Never" prepared questions before joining the online discussions or watching the videos.

So, the results disclosed that more than $80 \%$ of the learners were self-motivated by selecting a convenient time, choosing a comfortable location to avoid distractions and managing their time effectively since they got used to these practices before COVID19.

Besides, more than half of the respondents (52\%) stated that they "Never" prepared questions before joining the online discussion or watching the video since such a practice is specific to remote learning and they had not been trained before.

Moreover, the lack of certain self-regulation skills is revealed as the results showed that learners "Never" shared their learning problems (35\%) and neither checked for understanding with peers (44\%). This is correlated with $30 \%$ of learners who stated that online communication with peers "Never" helps them with the learning process.

According to Shea et al. (2012), three indicators are associated with self-regulated online learning. These indicators reflect how students a) plan and assign online tasks to themselves and to their peers, b) check for understanding and track their own performance on tasks with their peers, and c) admit the collaborative strategy by asking for or offering help to perform the required tasks.

Indeed, this study reflects the lack of self-regulation skills especially those related to online learning. Such an absence has consequences on learning presence (Banerjee, 2011; Brunner et al., 2015); an essential element of the Community of Inquiry (Col) Framework (Pool, 2017) which was added to the three interconnected presences (social, cognitive, and teaching). That is why, in an online learning environment, a stronger teaching presence is needed to support effective learning requirements. In the results of the study conducted by Owusu-Fordjour et al. (2020), more than 50\% of students agreed on the ineffectiveness of remote learning in comparison to physical attendance at school. This was due to the fact that most of the respondents were unable to study effectively at home because they considered that learning new concepts was rendered more difficult when studied alone. This aligns with the studies that describe teaching as a process that occurs when a more knowledgeable person passes on knowledge to a less knowledgeable one in order to induce a relatively permanent change in behavior (Bateman \& Waters, 2013).Finally, among the practices followed by the students, the findings of the two items "Using online communication tools helps me to understand the lessons very well" and "I am doing the required assignments for remote learning" were perceived statistically different between Grade 9 and Third Secondary learners.

Regarding the former item, almost $65 \%(\mathrm{~N}=309)$ of Grade 9 and $76 \%(\mathrm{~N}=343)$ of Third Secondary learners chose "Often" while around $25 \%(N=118)$ of them chose "Never" in comparison to $19 \%(N=86)$ of Third Secondary learners. This means that younger students were more affected by the personal communication interruption that took place during online learning.

As for the latter item, $55 \%$ ( $\mathrm{N}=249)$ of Grade 9 learners chose "Always" and 8\% ( $\mathrm{N}=38$ ) of them chose "Never" while 41\% ( $\mathrm{N}=183$ ) and $15 \%(\mathrm{~N}=67)$ of Third Secondary learners chose "Always" and "Never" respectively. This indicates that younger students showed more responsibility and awareness towards their learning and they took this experience more seriously than Third Secondary learners although both were supposed to sit for the Official Exams towards the end of the academic year. 
The learners' evaluation of the remote learning experience, their willingness to repeat it and their suggestions to improve virtual learning were also examined through the three open-ended questions of Section 3.

In Q1, the remote learning experience was assessed by students and the thematic analysis of the responses revealed that the students' evaluation would be classified into one of the five categories. The students' responses were mainly distributed into two groups: $44 \%$ of learners described the remote learning experience as "poor/not good/bad/unsuccessful /characterised by failure" as compared to $43 \%$ who considered it as a "successful/good/very good" and "ccceptable/not bad" experience.

Therefore, $56 \%$ of learners considered the remote learning experience asunsuccessful if we consider the percentage of learners who stated that online learning is not the best way to learn but they accepted it under certain severe circumstances (12\%). This perspective towards remote learning does not show any statistical difference between Grade 9 and Third secondary learners.

The perceptions of Lebanese students were also shown in the results of the study conducted during the same period by $\mathrm{Al}$ Rouadi and Anouti (2020) where $82 \%$ of students ( 628 out of 764 ) considered online learning a failure.

Q2 of Section 3 examined the students' willingness and readiness to go through the online learning experience again. The results showed that almost $70 \%$ of learners were not interested to go through this experience again (Figure 5). In fact, the responses to this question were strongly correlated with the results of Q1 (Figure7) and this strong relationship between the variables was found statistically significant.

Among learners who described their remote learning experience as a failure, $90 \%$ of them showed no interest to go through it again, while among those who described it as a successful one, $63 \%$ of them reported that they would accept to pass through it one more time.

In Q3 of Section 3, learners were asked to give one or more recommendations to improve online learning. Their recommendations were classified under two main categories. Almost $47 \%$ of learners ( $41 \%$ of Grade 9 and $53 \%$ of Third Secondary learners) suggested improving the infrastructure and providing the required facilities for students and teachers such as internet access, electricity, and digital tools. According to UNESCO (2020), the lack of access to technology and reliable internet connection to learners living in rural and lower socio-economic areas deepens the inequality among students while learning remotely. In addition, $55 \%$ of learners (52\% of Grade 9 and $58 \%$ of Third Secondary learners) suggested improving the implementation of online learning in all its aspects starting with planning, designing, delivering and monitoring. Around 18\% of learners -mostly Grade 9 students - recommended to give up on remote learning and return to schools.

The correlation between the descriptions attributed to remote learning in Q1 and the recommendations given in $\mathbf{Q} 3$ is presented in Figure 8.

Among students who recommended to quit remote learning and go back to school, $70 \%$ of them described it as "poor/bad/not good/ charcterised by failure or unsuccessful".

As for students who proposed adopting online learning as a part of blended learning, their description of their remote learning was dispersed. Thus, the remote learning experience was described as "successful" by $25 \%$ of them, "acceptable" by another $25 \%$ of them, "poor" by $28 \%$ of them and "ok" by $19 \%$ of themwho clarified that, "it is not the best way to learn; but it is a must in this situation." The remaining percentage (3\%) of students who suggested adopting blended learning included those who were not exposed to this experience since they had no internet connection at home.

This is an indicator that online learning has features which attract students due to its flexibility. In fact, $57 \%$ of Lebanese learners (Al Rouadi \& Anouti, 2020) selected the diversity of the explanation techniques, such as usage of educational videos as the reason that led to the success of online learning. This finding is in alignment with our results which show that $78 \%$ of learners considered using online communication channels helpful for understanding the lessons very well even though $56 \%$ of learners considered online lessons less effective than face-to-face learning.

Furthermore, among students who evaluated the remote learning experience as "poor", $34 \%$ of them suggested improving the infrastructure, while $40 \%$ of them suggested improving the online teaching strategies. So, the findings of Section 3 about learners' perceptions and attitudes show the correlation among the learners' evaluation of the remote learning experience, their interest to go through it again and their suggestions to improve it in the future.

Hence, for $44 \%$ of learners who described the remote learning experience as "poor", $90 \%$ of them showed no interest to go through it again and $70 \%$ of them proposed to quit remote learning and go back to school.

For $23 \%$ of learners who described the remote learning experience as "successful/good/very good", only $38 \%$ of them showed interest to go through it again whereas $62 \%$ of them rejected the idea completely or accepted it only either after tackling the problems or under certain severe circumstances. The suggestions of the respondents are almost equally distributed among improving the infrastructure (25\%), implementing a well-structured strategic plan (27\%) and adopting a blended model of learning $(25 \%)$ whereas $2 \%$ of them proposed to quit remote learning and go back to school.

Moreover, in this study, only a few learners (1\%) were not exposed to remote learning since they had no internet access at home. This may indicate that the poor infrastructure in Lebanon was not the main reason for student rejection of remote learning. These results showed that implementing remote learning requires ensuring a well-developed infrastructure and a well-designed pedagogy.

So, the results of this section disclose that the poor infrastructure was not the only barrier to remote learning. In fact, the absence of an implemented strategy for remote learning had a significant impact on this issue. Even though the teachers and students were rapidly able to adapt to using various communication channels such as Whatsapp, Zoom, Microsoft Teams, and others, the absence of a clear pedagogical approach affected the quality of online learning and instruction. 
Before COVID-19, teachers were not trained to teach in virtual learning environments, so they were all considered novice in delivering online sessions and they needed support to apply pedagogical methods and models. Moreover, no digital contentwhich fits the Lebanese context and aligns with the Lebanese curriculum adopted in all public and many private schools- was readily available for them. Furthermore, in the Official Exams run by the Ministry of Education and Higher Education, Grade 9 and Third Secondary learners are assessed based on the content of the Lebanese curriculum.

Hence, this study will help to assess the pedagogical approach for better planning, designing and delivering this mode of learning in the future.

So, teachers who started the experience of online instruction "in real-time" faced the challenges of communicating with their students, managing their virtual classrooms, keeping students in the learning atmosphere, and monitoring and assessing students' learning. Indeed, to succeed in implementing online learning, ensuring the learning presence is essential.

After experiencing online learning with all the opportunities and challenges, it was noticed that the Lebanese education system needs a 'Plan B' for safe and effective learning delivery when schools are closed in cases of crises. Moreover, setting a blended learning policy by MEHE is a must since in remote learning, many opportunities are offered such as the flexibility of learning, the feeling of comfort where students can log in at their comfort zones, and the self-paced learning. The policy framework ought to include procedures targeting to access online education for all citizens. Such procedures must include providing an infrastruture which ensures electricity and a reliable internet network. Moreover, for a successful online classroom, there is a need to ensure computers and ICT gadgets especially for disadvantaged students who come from low socio-economic families. During COVID-19, two or more students belonging to poor families had used one smart phone in online learning. Furthermore, many of the results showed that most students used their smart phones for their online learning. Furthermore, there is a need to establish a national learning management system (LMS) that allows teachers to track their students' progress. Ensuring quality in online learning depends on designing high quality e-lessons which align with the Lebanese curriculum.

In addition, to acquire the self-regulation skills, students must know about online security and the safe online practices which constitue a major part of digital, information and media literacies. Until now, all these literacies which create the profile of a digital citizen are still unidentified by the Lebanese education sector.

Furthermore, any online education framework should specify teachers' roles in this new paradigm. These roles include but are not limited to monitoring students' engagement by following up on their attendance and checking their progress; addressing the possible barriers to online learning; and providing individualized support to students based on their needs (Gouëdard et al., 2020). Finally, special attention has to be given to disengaged students by establishing different forms of communication to maintain contact with them, as well as by adopting a flexible curriculum limited to key competences in order to regain these students' confidence (OECD, 2020).

\section{Limitations}

The main limitation of this study is the small sample size. Hence, the results might not be reproducible if a larger sample was taken and if teachers' perspectives were considered.

\section{CONCLUSIONS}

In this paper, the attitudes of Lebanese students towards remote learning and their online learning practices were examined. The targeted sample of this study included public and private Grade 9 and Third Secondary learners where 928 of them responded to an online survey distributed by corresponding teachers. For the results, a range of statistical analyses was conducted. Tables of frequencies and percentages, and those of cross-tabulations were used to present categorical variables. Chi-square tests of independence were used to test for relationships between pairs of categorical variables and their strength by Chi-square meausres of association.

Since Section 3 consisted of open-ended questions, the researchers performed qualitative thematic content analysis based on the responses and Chi-squared test for nominal data. The results of Q1 in Section $\mathbf{2}$ show that $49 \%$ of learners stated that online lessons made them "Always" feel isolated because there is not any kind of interaction as compared to $18 \%$ who stated that they "Never" had this feeling. The effectiveness of online communication tools in this new learning environment and the online practices of learners in remote learning were examined in Q2 of Section 2. So, 76\% of Third Secondary learners "Often" understand their lessons deeply in comparison to $65 \%$ of Grade 9 learners. However, Grade 9 learners showed more responsibility towards their own learning since $55 \%$ of them "Always" did the required assignements as compared to $42 \%$ of Third Secondary learners.

Around 90\% of learners had "Always" or "Often" chosen an appropriate place to study and $85 \%$ of learners who had "Always" or "Often" chosen a time for studying their online lessons with few distractions.

Moreover, learners were asked to evaluate the remote learning experience. So, $44 \%$ of them described it as "poor" while $43 \%$ of them described it as "acceptable" or as "good". Besides, when students were asked about their willingness to go through the online learning experience again, $63 \%$ of them showed no interest in contrast to $10 \%$ only who showed interest. Additionally, students were asked about their recommendations to improve remote learning. So, around $47 \%$ of them recommended to improve the infrastructure and to provide all necessary facilities for students and teachers while $55 \%$ of them suggested adopting a clear and an adequate e-pedagogy that fits the Lebanese situation. 
As this paper might be considered among the fewest studies conducted in Lebanon to examine students' perceptions and attitudes about remote learning during the pandemic; it provides some but not sufficient information about key elements which could enhance future innovative adaptations to online teaching and learning.

Author contributions: All authors have sufficiently contributed to the study, and agreed with the results and conclusions.

Funding: No funding source is reported for this study.

Acknowledgements: The authors would like to whole heartedly thank the responding students who put some time into completing the survey. They would also like to express their deep gratitude to the school directors and teachers who showed readiness to pass the form electronically in order to facilitate the process of disseminating it to a large number of students.

Declaration of interest: No conflict of interest is declared by authors.

\section{REFERENCES}

Adnan, M. (2018). Professional development in the transition to online teaching: the voice of entrant online instructors. ReCALL, 30(1), 88-111. https://doi.org/10.1017/S0958344017000106

Atallah, T., \& Bou Melhem, I. (2020). Distance education in Lebanon: What it has and what it should. Nida Al Watan. https://www.nidaalwatan.com/article/17796

Bakia, M., Shear, L., Toyama, Y., \& Lasseter, A. (2012). Understanding the implications of online learning for educational productivity. US Dept of Education, Office of Educational Technology, Washington, DC.

Banerjee, G. (2011). Blended environments: Learning effectiveness and student satisfaction at a small college transition. Journal of Asynchronous Learning Networks, 15(1), 8-19. https://doi.org/10.24059/olj.v15i1.190

Bateman, A., \& Waters, J. (2013). Asymmetries of knowledge between children and teachers on a New Zealand bush walk. The Australian Journal of Communication, 40(2), 19-31.

Brunner, S., Brendenlier, S., Stoter, J., Hohlfeld, G., \& von Ossietzky, C. (2015). "Are they ready?” Self-directed learning readiness and acceptance of e-learning tools: Comparing non-traditional and traditional students. http://eurodl.org/materials/special/2015/Brunner_et_al.htm

Bücker, S., Nuraydin, S., Simonsmeier, B. A., Schneider, M., \& Luhmann, M. (2018). Subjective wellbeing and academic achievement: A meta-analysis. Journal of Research in Personality, 74, 83-94. https://doi.org/10.1016/j.jrp.2018.02.007

Burgess, S., \& Sievertsen, H. H. (2020). Schools, skills, and learning: The impact of COVID-19 on education. VoxEu.org. https://voxeu.org/article/impact-covid-19-education

Farah, M., \& Frayha, N. (2021). Lebanese teachers' perceptions of online learning. International Journal of Advanced Research in Science, Engineering and Technology, 8 (2), 16539-16547.

Flack, C. B., Walker, L., Bickerstaff, A., Earle, H., \& Margetts, C. (2020). Educator perspectives on the impact of COVID-19 on teaching and learning in Australia and New Zealand. Pivot Professional Learning.

Garrison, D. R., \& Arbaugh, J. B. (2007). Researching the community of inquiry framework: Review, issues, and future directions. Internet and Higher Education, 10, 157-172. https://doi.org/10.1016/j.iheduc.2007.04.001

Garrison, D. R., \& Cleveland-Innes, M. (2005). Facilitating cognitive presence in online learning: Interaction is not enough. American Journal of Distance Education, 19 (3), 133-148. https://doi.org/10.1207/s15389286ajde1903_2

Garrison, D. R., \& Vaughan, N. D. (2008). Blended learning in higher education: Framework, principles, and guidelines. Jossey-Bass. https://doi.org/10.1002/9781118269558

Gouëdard, P., Pont, B., \& Viennet, R. (2020). Education responses to COVID-19: Shaping an implementation strategy (OECD Education Working Papers, No. 224). https://doi.org/10.1787/8e95f977-en

Hanadi, S. M. (2021). University teachers' perceptions of online assessment during the COVID-19 pandemic in Lebanon. American Academic \& Scholarly Research Journal, 13(1), 11-24.

Holmberg, B. (2007). A theory of teaching-learning conversation. In M.G. Moore (Ed.), Handbook of distance education. Taylor \& Francis.

Jackson, C. (2009). Learning online: A report on distance eucation in LIS programs. ALAAPA.org. https://alaapa.org/newsletter/2009/05/13/learning-online-a-report-on-distance-education-in-lis-programs/

Luo, N., Zhang, M., \& Qi, D. (2017). Effects of different interactions on students' sense of community in elearning environment. Computers \& Education, 115, 153-160. https://doi.org/10.1016/j.compedu.2017.08.006

McKeon, J. (2014). An investigation into students' and teachers' perceptions of aspects of online learning. International Journal of Research in Humanities and Social Studies, 1(1), 64-76.

McLeod, S. A. (2019). Constructivism as a theory for teaching and learning. Simply psychology. https://www.simplypsychology.org/ constructivism.html

Means, B., Bakia, M., \& Murphy, R. (2014). Learning online: What research tells us about whether, when and how. Routledge. https://doi.org/10.4324/9780203095959

Moore, M. G., \& Kearsley, G. (2012). Distance education: A systems view of online learning. Wadsworth Cengage Learning. 
OECD. (2020). Education and COVID-19: Focusing on the long-term impact of school closures. OECD.org. http://www.oecd.org/coronavirus/policy-responses/education-and-covid-19-focusing-on-the-long-term-impact-of-schoolclosures-2cea926e/

Owusu-Fordjour, C., Koomson, C. K., \& Hanson, D. (2020). The impact of COVID-19 on learning -The perspective of the Ghanaian student. European Journal of Education Studies, 7, 3. https://doi.org/10.5281/zenodo.3753586

Peters, S., Barbier, M., Faulx, D., \& Hansez, I. (2012). Learning and motivation to transfer after an e-learning programme: Impact of trainees' motivation to train, personal interaction and satisfaction. Innovations in Education and Teaching International, 49(4), 64-76. https://doi.org/10.1080/14703297.2012.728878

Pool, J., Reitsma, G., \& van Den Berg, D. (2017). Revised community of inquiry framework: Examining learning presence in a blended mode of delivery. Online Learning, 21(3), 153-165. https://doi.org/10.24059/olj.v21i3.866

Reis, Z. A. (2010). Investigating the attitude of sudents towards online learning. International Journal of E-Adoption, 2(4), 35-47. https://doi.org/10.4018/jea.2010100103

Robbins, J. (2020). UNESCO: 290 million students stay home due to Coronavirus. In H. Do (Ed.), Learning English. https://learningenglish.voanews.com/a/unesco-290-million-students-stayhome-due-to-coronavirus/5317148.html

Rouadi, N., \& Anouti, M. (2020). The online learning experiment in the intermediate and secondary schools in Lebanon during the Coronavirus (COVID-19) crisis. International Journal of Advanced Research in Science, Engineering, and Technology, 7(7), 1446614485.

Survey on National Education Responses to COVID-19 School Closures. (2020). http://uis.unesco.org/en/files/covid19_school_closure_questionnaire_en-pdf

UNESCO. (2020). Startling digital divides in distance learning emerge. unesco.org. https://en.unesco.org/news/startling-digitaldivides-distance-learning-emerge

Zhang, Y., \& Lin, C.-H. (2020). Student interaction and the role of the teacher in a state virtual high school: What predicts online learning satisfaction? Technology, Pedagogy \& Education, 29(1), 57-71. https://doi.org/10.1080/1475939X.2019.1694061 